\title{
(C) OPEN ACCESS \\ When pneumonia does not respond to antibiotics: a challenging neonatal diagnosis
}

\author{
A J Jones, ${ }^{1}$ L D Starling, ${ }^{2}$ T Keith, ${ }^{1}$ R Nicholl, ${ }^{1}$ A N Seale ${ }^{2,3}$
}

\begin{abstract}
${ }^{1}$ Paediatric Department, Northwick Park Hospital, Harrow, UK.

${ }^{2}$ Department of Paediatric Cardiology, Royal Brompton and Harefield NHS Trust, London, UK ${ }^{3}$ Department of Paediatric Cardiology, Birmingham Children's Hospital, Birmingham, UK
\end{abstract}

\section{Correspondence to}

Dr Andrew J Jones, Paediatric Department, Northwick Park Hospital, Harrow HA1 3UJ, UK; andrewjones7@nhs.net

Received 10 April 2013 Revised 30 March 2014 Accepted 14 April 2014 Published Online First 16 May 2014

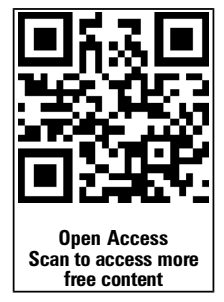

\section{CrossMark}

\footnotetext{
To cite: Jones AJ,

Starling LD, Keith T, et al.

Arch Dis Child Educ Pract Ed

2014;99:221-230.
}

\section{INTRODUCTION}

Baby girl C was born at $41^{+2}$ weeks, weighing $2.8 \mathrm{~kg}$, by vaginal delivery after induction of labour. This was the 24-year-old mother's first pregnancy, which was uncomplicated, with normal routine antenatal scans and serology. Her membranes ruptured $17 \mathrm{~h}$ prior to delivery: liquor was clear and there was no maternal peripartum pyrexia.

After delivery, initial bradycardia responded rapidly to airway manoeuvres and intermittent positive pressure ventilation, and the Apgar score was 10 at $10 \mathrm{~min}$.

The baby was given to her mother and had her first breast feed. There were no concerns and mother and baby were transferred to the postnatal ward.

The routine newborn examination at $8 \mathrm{~h}$ of age revealed a pink baby with warm peripheries and easily felt peripheral pulses. There were no signs of respiratory distress. No added heart sounds or murmurs were heard on auscultation and the baby was declared fit for discharge. Pulse oximetry screening was not performed.

\section{Comment: Routine oxygen saturation screening in the newborn}

The newborn check is completed to confirm the fitness of a baby for discharge and to screen for congenital abnormalities, specifically, developmental dysplasia of the hip, congenital cataracts, cryptorchidism and congenital heart disease (CHD). ${ }^{1}$

In 2005, a Health Technology Assessment (HTA) review of newborn screening for CHD concluded that the current system performs poorly, but that pulse oximetry screening may provide a promising adjunct to clinical examination alone. In the HTA model, only $32 \%$ of babies with lifethreatening CHD would be diagnosed by clinical examination alone. ${ }^{2}$
There is good evidence to explain why the routine newborn examination is suboptimal in identifying all cases of CHD. Half the babies in the postnatal ward with CHD have no distinctive murmur, while cyanosis may be difficult to detect clinically, particularly in non-Caucasian ethnic groups. ${ }^{3}$

In a study of infants with lifethreatening CHD from 1984 to 2004, $8 \%$ of cases were detected antenatally, $62 \%$ before discharge, $25 \%$ in living infants after discharge home, and 5\% at postmortem. ${ }^{4}$ One in three infants with a potentially life-threatening cardiac defect left hospital undiagnosed. A major UK survey from 1999 puts antenatal detection of major CHD at $23 \%,{ }^{5}$ and might be as high as $50 \%$ in some centres. ${ }^{6} 7$ Central Cardiac Audit Database data from April 2006 to March 2011, looking at detection of CHD requiring surgery or catheterisation in the first year of life, demonstrate antenatal diagnosis rates of $50-60 \%$ in parts of London, though significant geographical variation remains. ${ }^{8}$

Over recent decades, the duration of inpatient maternity stay has reduced. In $1980,39 \%$ of mothers stayed 0-3 days after delivery, with $28 \%$ staying 7 days or more. In 2009, 89.8\% stayed 0-3 days, with only $2.2 \%$ staying 7 days or more. ${ }^{9}$ With shorter postnatal stays there is the potential for a greater proportion of babies to be discharged from hospital with an as yet undiagnosed life-threatening CHD.

The evidence base for the efficacy of pulse oximetry as a screening tool for CHD in asymptomatic newborns has rapidly expanded in the last 10 years. Combining data from 13 studies and 229421 newborns, the overall sensitivity of pulse oximetry for detection of critical duct-dependent CHD is $76.5 \%(95 \% \mathrm{CI}$ $67.7 \%$ to $83.5 \%$ ), with specificity of $99.9 \%$ (95\% CI $99.7 \%$ to $99.9 \%$ ). ${ }^{10}$ The 
babies most likely to be missed by screening are those with an obstructed aorta (coarctation of the aorta and interrupted aortic arch). Among the false positives are conditions where early detection is potentially beneficial, such as symptomatic pulmonary hypertension and pneumonia.

Pulse oximetry would appear to meet criteria for universal screening, but concerns still exist regarding the cost of setting up such a programme, and the time and money that would need to be spent on investigating false positives. Data from the meta-analysis suggests an overall false positive rate of $0.14 \%$ (95\% CI $0.06 \%$ to $0.33 \%)$. This falls to $0.05 \%(95 \%$ CI $0.02 \%$ to $0.12 \%$ ) if screening is performed after $24 \mathrm{~h}$ of age. A cost effectiveness analysis performed on data from a large 2011 UK study ${ }^{11}$ estimated a cost of $£ 24000$ per case of timely diagnosis in a population in which antenatal screening for CHD already exists. $^{12}$ The authors conclude that a screening programme is likely to be cost effective.

Routine pulse oximetry screening can detect cases of critical CHD missed by antenatal ultrasonography and newborn examination, and thus by preventing circulatory collapse has potential benefits for neonatal mortality and long-term morbidity. As of now there is no national protocol for pulse oximetry screening of newborns, but one possible method is suggested here (box 1).

On the postnatal ward at $14 \mathrm{~h}$ of age, the midwife called the paediatrician to review the baby due to poor feeding. The mother reported the baby had not fed well since birth and did not want to suckle at the breast or bottle, though she had passed urine and meconium.

On examination, the baby was grunting and had intercostal recession with nasal flaring. Observations revealed a temperature of $37.5^{\circ} \mathrm{C}$ with a heart rate of $140 \mathrm{bpm}$ and respiratory rate of 70 breaths per minute. No murmur was heard and the femoral pulses were easily palpable. Abdominal examination was unremarkable with no hepatomegaly. Tone was normal and the anterior fontanelle soft.

\section{Comment: Spotting the unwell neonate on the postnatal ward}

When assessing a potentially unwell neonate, it is important to consider a range of differential diagnoses (box 2). One of the challenges encountered in neonatology is the non-specific presentation, with signs and symptoms which may represent primary respiratory or cardiovascular compromise, sepsis, or a metabolic disturbance. This conundrum necessitates a thorough, systematic and pragmatic approach to assessment and treatment (box 3).

The use of early warning systems is widespread in adult medicine, where a rise or fall in the physiological parameters of heart rate, blood pressure, temperature and respiratory rate outside of a specified range should trigger escalation. The aim is to identify
Box 1 Proposed method of routine saturation measurement, based on American Academy of Paediatrics algorithm: Screening for Critical Congenital Heart Defects ${ }^{14}$

Screening should be performed at the time of the routine newborn examination. Variation in the length of inpatient stay for mother and baby will necessitate a pragmatic approach to the time of screening.

- Probe should be placed sequentially on either foot (postductal), and on the right hand (preductal). There is data to suggest that measuring preductal and postductal saturations can increase detection of congenital heart disease. ${ }^{13} \mathrm{~A}$ preductal and postductal difference of $>3 \%$ should be considered abnormal.

- Baby should be awake but not struggling, and have regular breathing

- Record for at least 2 min

- Oxygen saturations should be $\geq 95 \%$

- Saturations of $90-94 \%$ should prompt a paediatric assessment and a repeat measurement in 4-6 h.

- Saturations below $90 \%$ should prompt a paediatric assessment and admission for further investigation, including echocardiography.

abnormality early, permitting timely intervention and preventing decompensation.

Early warning systems are becoming increasingly used in paediatrics. ${ }^{16}$ Evidence for their efficacy on clinical outcomes is not yet compelling, but they have not been shown to cause any harm, and it is biologically plausible that they should be useful. National guidelines now suggest that all paediatric departments should make use of such systems, although there is, as of now, no standardised approach. Such systems are rarely used on the postnatal ward, but a UK-based group has demonstrated that a newborn early warning

Box 2 Differential diagnosis of dyspnoea in the neonate $^{15}$

Transient tachypnoea of the newborn

- Septicaemia, especially group B streptococcal (GBS) pneumonia

- Meconium aspiration

- Respiratory distress syndrome (RDS)

- Birth asphyxia and acidaemia

Pneumothorax, pneumomediastinum

Congenital defects

Congenital heart disease

Diaphragmatic hernia

Lung malformations 
Box 3 Focussed history when assessing the sick neonate

- Main concern of the mother or midwife: poor feeding, fever, breathing problems, sleepiness; abnormal colour, movements or noises.

- Problems in pregnancy: antenatal scans, additional tests, gestational diabetes.

- Labour and delivery: mode of delivery, complications, presence of meconium, offensive smelling liquor, condition at birth (Apgar scores), need for resuscitation, cord gases.

- Risk factors for sepsis: maternal bacterial colonisation (eg, group B streptococcus (GBS), Escherichia coli), prolonged rupture of membranes, evidence of maternal infection.

- Maternal medical and drug history: diabetes mellitus and control, other endocrine disorders, infections, opiates in labour, potentially teratogenic medications, drugs of abuse.

- Family history: consanguinity, congenital heart disease, metabolic disorders.

- Bedside investigations: oxygen saturations, temperature, blood glucose, blood gas (including lactate).

(NEW) system prompted earlier review in those demonstrating clinical deterioration, and prompted intervention where required (table 1). ${ }^{17}$ In this small prospective study 9 of 19 infants requiring intervention were detected by the early warning system. Implementation of this system on the postnatal ward could be a useful tool in identifying the unwell baby at an earlier stage, but might add to the workload of midwifery and nursing staff. Midwifery staff reported that the charts were beneficial, and served as a useful reminder of the normal physiological parameters in newborns.

Suspected sepsis is a common diagnosis recorded on the postnatal ward and neonatal unit. Early onset sepsis is defined by the Vermont Oxford Networks as sepsis with onset at $<72 \mathrm{~h}$ of age. Early onset sepsis is usually vertically transmitted and acquired prenatally or perinatally from organisms within the birth canal or amniotic fluid. ${ }^{18}$ Group B Streptococcus (GBS) is the most common pathogen in term infants, while Escherichia coli is most prevalent in preterm infants. Risk factors for GBS sepsis are described in box 4. Early onset sepsis, with a positive blood culture, has $16 \%$ mortality, and more infants die from $E$ coli than from GBS infection. However E coli and GBS are equally likely to cause death when mortality rates are adjusted for gestational age. ${ }^{19}$

Prematurity alone is the risk factor most closely associated with early onset neonatal sepsis. Preterm babies have an immature immune system, and preterm
Table 1 NEW system criteria

\begin{tabular}{llll}
\hline & Normal & Amber & Red \\
\hline Temperature $\left({ }^{\circ} \mathrm{C}\right)$ & $36.3-37.5$ & $\begin{array}{l}35.5-36.3 \\
37.5-38\end{array}$ & $<35.5$ \\
& & $20-30$ & $<20$ \\
& $30-60$ & $60-80$ & $>80$ \\
$\begin{array}{l}\text { Respiration } \\
\text { (breaths per minute) }\end{array}$ & & $\begin{array}{l}\text { Grunting } \\
\text { present }\end{array}$ & $\mathrm{N} / \mathrm{A}$ \\
Grunting & No grunting & \\
& & $70-90$ & $<70$ \\
$\begin{array}{l}\text { Heart rate } \\
\text { (beats per minute) }\end{array}$ & $90-150$ & $150-190$ & $>190$ \\
Colour $\left(\mathrm{SpO}_{2}\right) \%$ & $>94$ & $90-94$ & $<90$ \\
Neurology & Active/wakes & Jittery/ & Floppy/difficult \\
& to feed & irritable & $\begin{array}{l}\text { to rouse } \\
\text { Seizures }\end{array}$ \\
\hline
\end{tabular}

One amber observation: Contact SHO/ANNP/Senior midwife. Verbal management plan or review. Repeat observations in $30 \mathrm{~min}$. Two amber or one red observation: immediate review.

NEW, newborn early warning.

birth is associated with the highest rates of chorioamnionitis and complications of labour.

The National Institute of Health and Care Excellence (NICE) guidelines recommend the use of intravenous intrapartum antibiotics to reduce the risk of early onset neonatal infection. ${ }^{21}$ Absolute indications are a previous baby with an invasive GBS infection; and GBS colonisation, bacteriuria or infection in the current pregnancy. Antibiotics should be considered in preterm labour if there is prelabour rupture of

Box 4 Risk factors for group B streptococcus (GBS) sepsis $^{20}$

Baseline risk: 1.8 culture-proven cases per 1000 live births

- Preterm birth/low birth weight <37 weeks $\leq 2500 \mathrm{~g}$ : OR 11.4

1 Prolonged rupture of membranes $>18 \mathrm{~h}: \mathrm{OR} 7.28$

- Intrapartum fever $>37.5^{\circ} \mathrm{C}$ : OR 4.05

- Chorioamnionitis* Present: OR 6.43

- Maternal vaginal culture at delivery Any GBS positivity: OR 204

- Maternal rectovaginal culture at 28 weeks Any GBS positivity: OR 9.64; already delivered OR 51.7

- Maternal rectovaginal culture at 36 weeks Any GBS positivity OR 26.7; already delivered OR 32.9 Factors also associated with high risk:

- GBS bacteriuria

- Preterm premature rupture of membranes

- Sibling or twin with invasive GBS disease

*Intrapartum fever accompanied by two or more additional signs, including fetal tachycardia, uterine tenderness, offensive smelling liquor, or maternal leucocytosis. 
membranes of any duration, or intrapartum rupture of membranes lasting longer than $18 \mathrm{~h}$.

On arrival to the neonatal unit, oxygen saturations were $89 \%$ in air (preductally and postductally), with a respiratory rate which peaked at 90 breaths per minute. Supplementary oxygen was commenced via nasal cannulae at $0.3 \mathrm{~L} / \mathrm{min}$ with an increase in saturations to $92 \%$. A chest radiograph showed bilateral patchy airspace shadowing and a normal cardiac silhouette. C-Reactive Protein (CRP) was 18, but otherwise, routine bloods were unremarkable with no leukocytosis. An attempted lumbar puncture was unsuccessful. Empirical broad-spectrum intravenous antibiotics (benzylpenicillin and gentamicin) were commenced, in accordance with local protocol, along with intravenous fluids and nasogastric feeds.

The working diagnosis at this juncture was sepsis, most likely of chest origin. The baby initially required 0.25 to $0.3 \mathrm{~L} / \mathrm{min}$ of oxygen to maintain saturations $>90 \%$, and had a chest radiograph suggestive of pneumonia with a raised CRP.

Over the following week, the baby remained in up to $0.3 \mathrm{~L} / \mathrm{min}$ of oxygen, with the aim of maintaining saturations above $92 \%$, and she completed 7 days of antibiotics. However, the respiratory rate was persistently raised, between 60 and 90 breaths per minute. Repeated capillary blood gases did not indicate a metabolic or respiratory acidosis. Blood cultures were sterile after 5 days of incubation.

On day 7 , she deteriorated with worsening hypoxia and an increased work of breathing. Peak respiratory rate was 110 breaths per minute, but with a capillary blood gas that did not indicate any deterioration in ventilation (table 2). Continuous positive airway pressure (CPAP) was initially commenced, with a positive end expiratory pressure (PEEP) $8 \mathrm{~cm} \mathrm{H}_{2} \mathrm{O}$ and $\mathrm{FiO}_{2}$ $100 \%$, with oxygen saturations of $85 \%$.

To try and improve oxygenation she was paralysed, sedated and invasively ventilated.

Ventilation settings were: conventional mandatory ventilation (CMV), peak inspiratory pressure (PIP) $26 \mathrm{~cm} \mathrm{H}_{2} \mathrm{O}$, PEEP $4 \mathrm{~cm} \mathrm{H}_{2} \mathrm{O}$, rate 60 , inspiratory time $0.4 \mathrm{~s}, \mathrm{FiO} 2100 \%$. On these settings the oxygen saturations were $92 \%$.

Investigations were repeated. A chest X-ray showed generalised hazy shadowing, thought to represent an infectious process, with normal cardiac silhouette (figure 1); while the CRP had normalised and the full blood count and renal function remained unremarkable. Blood cultures were repeated and antibiotics were changed to ceftazidime and vancomycin given the presumed poor response to benzylpenicillin and gentamicin. Due to the persistently low oxygen saturations, a transthoracic echocardiogram was performed at this stage by a consultant neonatologist, in which the heart appeared structurally and functionally normal.
Table 2 Initial capillary blood results

\begin{tabular}{lll}
\hline & Patient result & Normal range \\
\hline $\mathrm{pH}$ & 7.35 & $7.36-7.42$ \\
$\mathrm{pCO}_{2}$ & $5.13 \mathrm{KPa}$ & $4.3-6.1$ \\
$\mathrm{pO}_{2}$ & $5.55 \mathrm{KPa}$ & $11.3-14.0$ \\
Bicarbonate & $20.6 \mathrm{mmol} / \mathrm{L}$ & $21-35$ \\
Base excess & $-4.5 \mathrm{mmol} / \mathrm{L}$ & -2.0 to +2.0 \\
Glucose & $6.3 \mathrm{mmol} / \mathrm{L}$ & $2.5-5.3$ \\
Haemoglobin & $20.4 \mathrm{~g} / \mathrm{dL}$ & $18.0-21.0$ \\
White cell count & $27.4 \times 10^{9} / \mathrm{L}$ & $9.0-30.0$ \\
Neutrophils & $25.4 \times 10^{9} / \mathrm{L}$ & $6.0-26.0$ \\
Sodium & $136 \mathrm{mmol} / \mathrm{L}$ & $136-145$ \\
Potassium & $5.2 \mathrm{mmol} / \mathrm{L}$ & $4.0-5.5$ \\
Creatinine & $121 \mu \mathrm{mol} / \mathrm{L}$ & $25-115$ \\
Urea & $5.2 \mathrm{mmol} / \mathrm{L}$ & $2.5-6.6$ \\
Corrected calcium & $2.08 \mathrm{mmol} / \mathrm{L}$ & $1.72-2.47$ \\
CRP & & $<10$ \\
Day 1 & $18 \mathrm{mg} / \mathrm{L}$ & \\
Day 2 & $35 \mathrm{mg} / \mathrm{L}$ & \\
Day 5 & $<5 \mathrm{mg} / \mathrm{L}$ & \\
\hline
\end{tabular}

\section{Comment: Re-evaluation after no improvement}

The initial working diagnosis in this case was congenital pneumonia, made on the basis of respiratory distress at $16 \mathrm{~h}$ of life and a chest radiograph consistent with pneumonia; however, after 7 days of first-line empirical antibiotics, no improvement was seen.

Whilst chest radiography was suggestive of infection, the findings were non-specific and could represent pulmonary vascular markings secondary to CHD. Echocardiography reportedly demonstrated a structurally normal heart with no evidence of elevated pulmonary arterial pressure and no right-to-left shunt appreciated, however the baby remained hypoxic despite respiratory support. The blood glucose

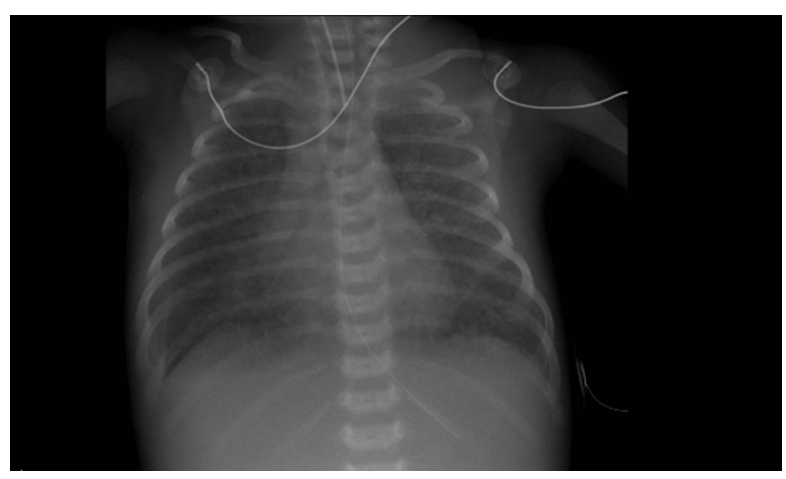

Figure 1 A chest radiograph performed after intubation. 
Table 3 Arterial blood gas in 100\% oxygen

\begin{tabular}{lll}
\hline & Patient result & Normal range \\
\hline $\mathrm{pH}$ & 7.41 & $7.36-7.42$ \\
$\mathrm{pCO}_{2}$ & $5.92 \mathrm{kPa}$ & $4.3-6.1$ \\
$\mathrm{pO}_{2}$ & $6.57 \mathrm{kPa}$ & $11.3-14.0$ \\
Bicarbonate & $27.5 \mathrm{mmol} / \mathrm{L}$ & $21-35$ \\
Base excess & $2.3 \mathrm{mmol} / \mathrm{L}$ & -2.0 to +2.0 \\
\hline
\end{tabular}

remained within normal limits and there was no other evidence to suggest an inborn error of metabolism (normal acid-base status and no signs of encephalopathy). The team was concerned that something was being missed as the infant's clinical condition continued to deteriorate despite conventional therapy.

By day 9 the baby had not improved prompting a trial of high frequency oscillatory ventilation (HFOV). With mean airway pressure (MAP) 15 , amplitude $(\Delta \mathrm{P})$ 56, Frequency $10 \mathrm{~Hz}$ and $\mathrm{FiO}_{2} 100 \%$ the oxygen saturations were $90 \%$ (table 3). An arterial line was sited at this stage and blood was drawn for a gas.

\section{Comment: Neonatal hypoxaemia and cyanosis}

Subnormal oxygenation of arterial blood can result in cyanosis (from the Greek, kyanos, for blue), a bluish discolouration of the skin or mucous membranes reflecting an increased concentration of deoxygenated haemoglobin $(>3-5 \mathrm{~g} / \mathrm{dL})$. Cyanosis is dependent upon the absolute concentration of reduced (deoxygenated) haemoglobin and not the oxygen saturation, thus, infants with polycythaemia are cyanotic at higher arterial saturations than those who are anaemic. ${ }^{22}$

Cyanosis occurs when there is excessive oxygen extraction in the tissues (resulting in peripheral cyanosis) or decreased oxygen saturation of the systemic arterial blood (resulting in central cyanosis). Transient cyanosis of the extremities or perioral region, is a common, non-pathological phenomenon often precipitated by exposure to the cold, while oxygen saturations remain normal. ${ }^{23}$

From a cardiac perspective, cyanosis is a manifestation of right-to-left shunting at any level of the circulation or of common mixing of deoxygenated and oxygenated blood.
Cyanosis can be difficult to detect clinically in newborns, particularly in borderline hypoxaemia, hence the usefulness of pulse oximetry screening for CHD.

The differential diagnosis of cyanosis in the neonate is described in tables $4-6 .^{22-24}$

\section{Comment: Pulmonary causes}

This infant was centrally cyanosed. The examination findings and air space shadowing on chest X-ray would be consistent with a pulmonary cause. However, oxygen saturations did not normalise with $100 \%$ oxygen, with a contemporaneous arterial blood gas showing a low $\mathrm{pO}_{2}$ of $6.57 \mathrm{kPa}$. Additionally, the baby's ability to self-ventilate did not deteriorate, despite worsening signs of respiratory distress and hypoxia. The blood gas $\mathrm{pCO}_{2}$ was always in the normal range. These factors taken together would make a pulmonary cause much less likely and other pathologies should be considered.

\section{Comment: Cardiac causes}

By this stage, optimal empirical management of suspected pneumonia had yielded no observable benefit. Alveolar ventilation was seemingly adequate, there was no overt evidence of an alternative pulmonary parenchymal pathology and conventional markers of inflammation had normalised. The 'hyperoxia' test (or so-called 'nitrogen washout' test) demonstrated a $\mathrm{pO}_{2}$ only minimally responsive to prolonged exposure to $100 \%$ oxygen, providing further evidence against primary respiratory disease and suggesting the presence of congenital cyanotic heart disease. In such a scenario, it is vital that specialist echocardiography is performed to formally assess the cardiac structure.

The clinical picture was one of persistent desaturation (with initial increased respiratory effort) in the context of a seemingly normal cardiac examination, but for evolving liver enlargement (now extending $3 \mathrm{~cm}$ beneath the right costal margin).

The above constellation is strongly suggestive of a unifying diagnosis of obstructed total anomalous pulmonary venous connection (TAPVC). Obstructed infracardiac TAPVC is a difficult diagnosis even when performed by the most experienced echocardiographer. Chest X-ray changes were non-specific, but a normal cardiac silhouette with diffuse reticular

Table 4 Peripheral cyanosis: inadequate oxygen supply to extremeties

\begin{tabular}{lll}
\hline Problem & Mechanism & Presentation and investigations \\
\hline Infection & $\begin{array}{l}\text { Sepsis creates an increased metabolic demand. The infant may be } \\
\text { unable to meet the increased oxygen requirements of the tissues } \\
\text { leading to peripheral vasoconstriction and cyanosis. }\end{array}$ & $\begin{array}{l}\text { In septicaemia, other clinical signs would be evident: tachycardia, } \\
\text { hypotension, metabolic acidosis; as well as signs of the underlying } \\
\text { infection. }\end{array}$ \\
Shock & $\begin{array}{l}\text { Inadequate blood flow to essential organs will result in peripheral } \\
\text { vasoconstriction. This can cause peripheral cyanosis. }\end{array}$ & $\begin{array}{l}\text { are pink. Systemic arterial oxygen saturations are normal. } \\
\text { arete that peripheral cyanosis is a not uncommon finding in normal } \\
\text { hypothermia }\end{array}$ \\
\hline
\end{tabular}


Table 5 Pulmonary causes of central cyanosis

\begin{tabular}{|c|c|c|}
\hline Problem & Mechanism & Presentation and investigations \\
\hline $\begin{array}{l}\text { Parenchymal disease: } \\
\text { Pneumonia } \\
\text { Respiratory Distress Syndrome (RDS)/Surfactant deficiency } \\
\text { Transient tachypnoea of the newborn } \\
\text { Meconium aspiration } \\
\text { Congenital abnormality leading to pulmonary hypoplasia: } \\
\text { diaphragmatic hernia, congenital cystic adenomatoid } \\
\text { malformation (CCAM) }\end{array}$ & $\begin{array}{l}\text { Pulmonary disease } \\
\text { leads to impaired } \\
\text { alveolar gas exchange } \\
\text { resulting in decreased } \\
\text { arterial oxygen } \\
\text { saturations }\end{array}$ & $\begin{array}{l}\text { History: risk factors for sepsis, meconium, oligohydramnios, } \\
\text { prematurity, abnormal antenatal scans. } \\
\text { Examination: tachypnoea, intercostal recession, use of accessory } \\
\text { muscles, crackles, wheeze. Cyanosis may improve on crying. } \\
\text { CXR: cardiac shadow normal, lung fields will most likely be } \\
\text { abnormal. } \\
\text { Gas: raised pCO } \mathrm{PCO}_{2} \text { and respiratory acidosis. } \\
\text { Saturations: no difference in preductal and postductal readings, } \\
\text { oxygen saturations will usually normalise in 100\% oxygen. } \\
\text { Normal ECG and echocardiogram }\end{array}$ \\
\hline $\begin{array}{l}\text { Alveolar ventilation: } \\
\text { Neuromuscular hypoventilation: Spinal muscular atrophy, } \\
\text { congenital myopathy, congenital myotonic dystrophy } \\
\text { Central hypoventilation syndrome }\end{array}$ & $\begin{array}{l}\text { Progressive } \\
\text { hypoventilation will } \\
\text { ultimately lead to } \\
\text { hypoxia }\end{array}$ & $\begin{array}{l}\text { History: may be family history of neurological disorder, respiratory } \\
\text { distress since birth, unable to wean from ventilator. } \\
\text { Examination: neurological signs: hypotonia, reduced reflexes, poor } \\
\text { suck, abdominal breathing }\end{array}$ \\
\hline
\end{tabular}

shadowing is consistent with pulmonary venous congestion due to obstructed TAPVC.

The baby was transferred to the nearest tertiary cardiac centre for a specialist paediatric cardiology opinion. Echocardiography demonstrated obstructed TAPVC of the infracardiac type. Urgent corrective surgery was performed the following day.

\section{Comment: TAPVC (also known as Total Anomalous Pulmonary Venous Drainage)}

TAPVC is a rare form of CHD, accounting for approximately $1-1.5 \%$ of all cases of CHD. ${ }^{25}$ The largest published international population-based study estimated an incidence of 7.1 cases of TAPVC per 100000 live births. ${ }^{26}$

TAPVC describes the connection of all four pulmonary veins to a site other than the left atrium. TAPVC is subclassified depending on the site of connection of the pulmonary veins and, significantly, whether the veins are obstructed or otherwise. The most common subtype, accounting for an estimated $48.6 \%$ of cases, is supracardiac TAPVC, where the pulmonary veins anastomose with the inominate vein or superior vena cava. Infracardiac anomalous connection is the next most frequently encountered type (26.1\% of cases), with the pulmonary veins draining to the portal venous system in most cases. Intracardiac TAPVC (15.9\% of cases) describes anomalous drainage to the coronary sinus in the majority of cases (or less commonly, directly to the right atrium), while the least common mixed subtype (8.8\% of TAPVC), usually comprises combined supracardiac and intracardiac anomalous connections. Approximately half the cases of TAPVC are obstructed at presentation, with the site of obstruction either along the course of the vein or at the site of anastomosis with the systemic venous system. Infracardiac TAPVC is the most commonly obstructed subtype, while a cardiac anomalous connection seemingly protects against obstruction.
Anomalous connection of the pulmonary veins to the systemic venous system (and thence the right atrium) means that the right atrium effectively receives systemic and pulmonary venous return. An interatrial communication (patent foramen ovale or atrial septal defect) is required to allow passage of the mixed deoxygenated and oxygenated blood from the right atrium into the left atrium and then the systemic circulation. Patients with a small interatrial communication present with low cardiac output. Absence of an interatrial communication is not compatible with life.

In cases where the pulmonary veins are obstructed, the return of oxygenated blood to the heart is impeded. Consequently, the proportion of oxygenated blood in the right atrium is reduced, thus, greater desaturation follows. Furthermore, obstruction to the pulmonary venous return leads to back-pressure in the pulmonary venous system, resulting in pulmonary venous congestion, which has a classical chest X-ray appearance. Clinically, this manifests as worsening desaturation and an increased work of breathing as seen in this case.

TAPVC is seldom diagnosed antenatally. An international multicentre collaborative study reported that, of 422 cases of TAPVC diagnosed, only eight cases $(1.9 \%)$ were identified antenatally. ${ }^{27}$ Most cases of TAPVC present in the first weeks to months of life with obstructed TAPVC understandably presenting earlier. Less than half the cases (an estimated 39\%) present prior to initial hospital discharge after birth. The most common presenting symptoms are cyanosis (43.1\%), respiratory distress $(31.8 \%)$, failure to thrive (11.1\%), and circulatory collapse (4.5\%).

As in the case described, by virtue of the non-specific clinical features, TAPVC frequently masquerades as other much more commonly encountered neonatal diseases processes. An awareness of TAPVC as a potential differential diagnosis in the context of the above clinical features is vitally important, particularly where, as in the 
Table 6 Central cyanosis: cardiac causes (some cardiac conditions can be placed in more than one category)

Problem Mechanism Presentation and investigations

Right-to-left shunts:

Tetralogy of Fallot (ToF)

Severe/critical pulmonary stenosis (PS)

Pulmonary atresia (PA) with or

without ventricular septal defect (VSD)

Ebstein anomaly (with interatrial

communication)

Persistent pulmonary hypertension of

the newborn (PPHN)
Increased right heart pressure, often secondary to right ventricular outflow tract obstruction or persistence of the fetal circulation (PPHN), leads to diminution or reversal of the usual systemic-to-pulmonary pressure gradient.

An atrial or ventricular septal defect \pm PDA permits right-to-left shunting, thereby allowing desaturated blood into the systemic circulation, resulting in cyanosis

Desaturated systemic venous blood and oxygenated pulmonary venous blood are allowed to freely mix at the atrial level (as in TAPVC or tricuspid atresia), at the ventricular level (as in double-inlet ventricles), or at the arterial level (as in truncus arteriosus), thereby desaturating the systemic arterial blood.

Systemic arterial oxygen saturations are directly proportional to pulmonary bloodflow

Parallel systemic and pulmonary circulations where deoxygenated blood recirculates through the systemic circulation and oxygenated blood recirculates through the pulmonary circulation. Left-to-right (systemic-to-pulmonary) flow across a PDA increases pulmonary bloodflow*, thereby increasing left atrial pressure, facilitating left-to-right flow across an interatrial communication, which ultimately permits passage of oxygenated blood into the systemic circulation
History: may have antenatal diagnosis; features of fetal distress likely in PPHN; may be cyanotic from birth; significant deterioration or circulatory collapse following ductal closure in duct-dependent pulmonary circulation (as in critical PS).

Examination: possible syndromic features (eg, 22q11 deletion); cyanosis, low saturations with possible discrepancy in preductal and postductal saturations (as in PPHN); increased intensity (PPHN) or absence (PA) of the pulmonary component to the second heart sound $\left(P_{2}\right)$; murmur reflecting underlying defect(s).

CXR: abnormal cardiac silhouette (size and shape); hypoplasia/ absence of the main pulmonary artery ('pulmonary artery bay'); possible right aortic arch; oligaemic lung fields.

Gas: low $\mathrm{pO}_{2}$; possible metabolic/lactic acidosis.

Echocardiogram: diagnostic; important to delineate presence of PDA and direction of ductal flow during cardiac cycle

History: may have antenatal diagnosis (unlikely in TAPVC); cyanosed from birth; respiratory distress where pathophysiology results in pulmonary congestion (as in obstructed TAPVC).

Rapid deterioration or circulatory collapse ensues when: (1) systemic circulation is reliant on mixing via an interatrial communication (eg, tricuspid atresia, TAPVC) that is too small ('restrictive'). The basis for the balloon atrial septostomy; (2) the arterial duct closes where the systemic circulation is duct-dependent.

Examination: reflects underlying defect(s) and presence of coexisting anomalies; possible syndromic features; may be cyanotic from birth; possible features of low cardiac output.

CXR: Reflects underlying defect(s) and coexisting anomalies-may be dextrocardia and abdominal situs inversus; abnormal cardiac silhouette; lung fields may be oligaemic, plethoric (eg, un-obstructed TAPVC) or there may be pulmonary venous congestion (as in obstructed TAPVC).

Gas: low $\mathrm{pO}_{2}$; metabolic/lactic acidosis if haemodynamic compromise. Echocardiogram: diagnostic; important to delineate presence of interatrial communication, size and direction/velocity of bloodflow across; and presence of PDA and direction of ductal flow during cardiac cycle

History: may have antenatal diagnosis; generally cyanosed from birth; circulatory collapse in the absence of a defect allowing mixing, when the interatrial communication is restrictive, or following ductal closure; if large VSD may become breathless when pulmonary vascular resistance drops.

Examination: desaturated preduct and postduct with cyanosis; possible features of low cardiac output if restrictive interatrial communication or congestive cardiac failure if large VSD; no murmur in the absence of associated defects such as VSD with PS ; often large babies.

CXR: Can be normal at birth. An 'egg-shaped' heart with narrow mediastinum is classically described; pulmonary plethora is seen when a large ductus or a VSD is present.

Gas: low $\mathrm{pO}_{2}$ with low saturations; metabolic/lactic acidosis if haemodynamic compromise; high incidence of hypoglycaemia. Echocardiogram: diagnostic (ventriculo-arterial discordance); important to note presence of associated defects (ie, VSD, PS); important to delineate presence of interatrial communication, size and direction/velocity of blood flow across; important to delineate presence of PDA case above, conventional management approaches are unsuccessful and the baby is deteriorating.

Clinical examination findings may not be obvious or specific. Synchronisation of the aortic and pulmonary components of the second heart sound (S2), culminating in a loud, single S2 may occur with obstructed TAPVC, while hepatomegaly may be marked in the obstructed infracardiac subtype. Conversely, unobstructed TAPVC may be associated with exaggerated splitting of the S2 (A2-P2) with a loud P2 and tricuspid flow murmur, all reflecting volume and pressure loading of the right heart. 


\section{Box 5 Echocardiography}

Echocardiography is diagnostic but challenging, particularly to the inexperienced echocardiographer, but several factors should raise suspicion. Where pure right-to-left shunting is observed across an interatrial communication in the presence of right heart volume-loading, identification of all four pulmonary veins is mandatory and should prompt urgent paediatric cardiology assessment where this is not possible, especially in the context of clinical deterioration (figures 2 and 3 ).

Several routine investigations may raise the index of suspicion for TAPVC. A chest X-ray will routinely be performed in the infant with respiratory distress. Pulmonary venous congestion in the absence of cardiomegaly is compatible with obstructed TAPVC and gets worse with time, while in non-obstructed cases, pulmonary oedema with a dilated right atrium and right ventricle (resulting in marked cardiomegaly) is observed. A blood gas taken from an umbilical venous catheter (UVC) may appear erroneously saturated (but should not be dismissed) and may be a subtle clue to the presence of infracardiac TAPVC. ${ }^{28}$ As a rightward QRS axis is the norm in early neonatal life, a 12-lead ECG provides little useful supplementary information (box 5).

Definitive treatment is surgical in all cases, with reconnection of the pulmonary veins to the left atrium. Timing of surgery is partly dependent on the presence of obstruction, which itself influences age and severity of presentation: obstructed cases require emergency surgery, while unobstructed cases are

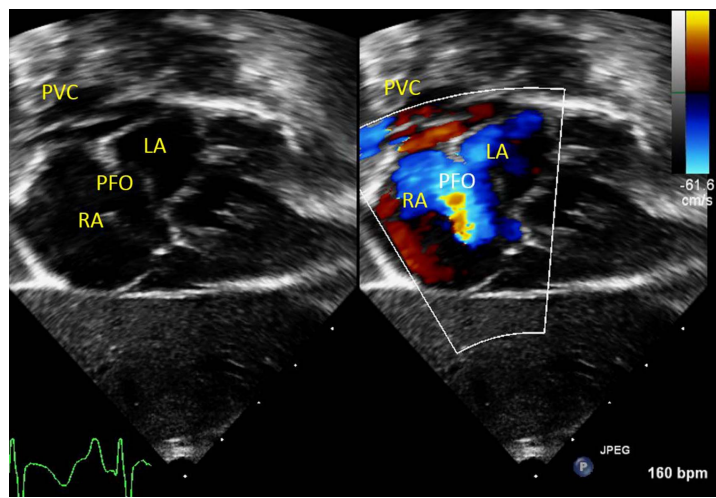

Figure 2 This subcostal four-chamber view demonstrates how the pulmonary veins join at the confluence (pulmonary venous confluence, PVC) before draining anomalously into the systemic venous system and then the right atrium (RA). The RA, therefore, receives the entire systemic and pulmonary venous drainage and is consequently dilated. Blood flows down its pressure gradient from the RA, across the patent foramen ovale (PFO), and into the left atrium (LA). Whenever a right to left flow across the atrial septum is observed it is vital that the location of the pulmonary venous drainage is confirmed.

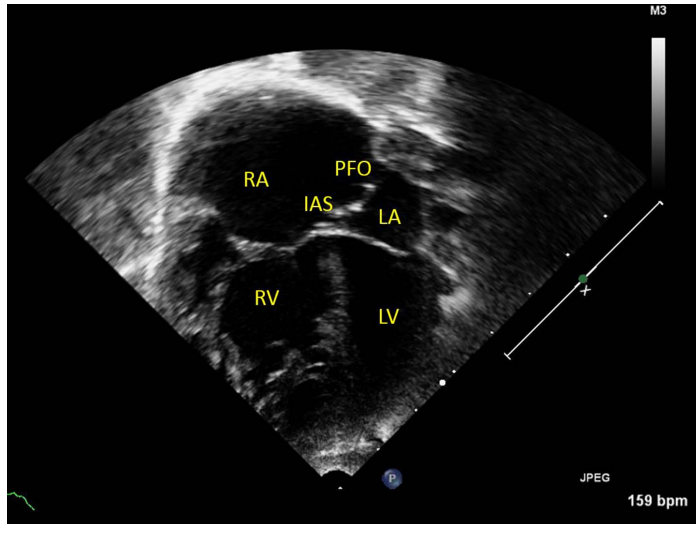

Figure 3 This apical four-chamber view demonstrates how the dilated right atrium (RA) and right ventricle (RV) are compressing the left atrium (LA) and left ventricle (LV), as all systemic and pulmonary venous blood returns to the right heart. The interatrial septum (IAS) characteristically bows towards the LA and blood will flow across the patent foramen ovale (PFO), from RA to LA, down its pressure gradient.

electively repaired between the ages of approximately 2 and 4 months (figure 4). Prior to surgery, diuretics (furosemide and spironolactone) may improve congestive cardiac failure in patients with unobstructed TAPVC. A restrictive interatrial communication limits cardiac output and may require a transcatheter balloon atrial septostomy, which should be performed in an appropriate environment with cardiac surgical back-up, such as the catheterisation laboratory or paediatric intensive care unit. Theoretically, obstructed TAPVC is an exceptional case of cyanotic CHD where a prostaglandin $\mathrm{E}$ infusion may be harmful by means of further increasing pulmonary blood flow and thereby worsening pulmonary venous congestion. However, if there is a concern regarding cyanotic CHD and diagnosis is unknown, do not be deterred in starting a prostaglandin infusion.

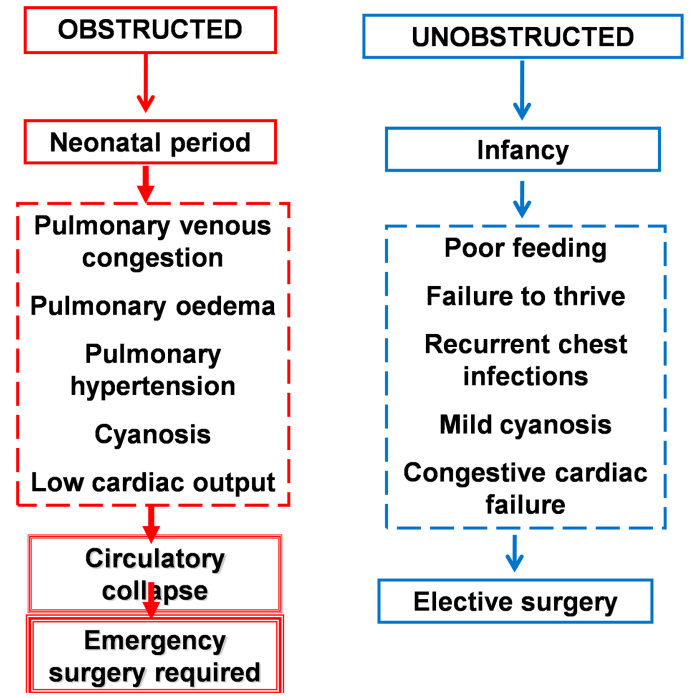

Figure 4 Presentation of total anomalous pulmonary venous connection (TAPVC). 


\section{CONCLUSION}

The frequently non-specific presentation of the unwell neonate provides a challenging diagnostic conundrum. The diagnosis may initially appear quite clear-respiratory distress, raised inflammatory markers and chest $\mathrm{X}$-ray features all apparently suggestive of pneumoniabut all may not be as it seems. As the clinical picture evolves, so does the differential diagnosis, and the clinician must remain open minded, malleable and equipped with a broad knowledge of potential pathologies that may account for a constellation of clinical signs.

In this case, the suspected diagnosis of pneumonia was very plausible-a case made stronger by its relatively common nature. However, the lack of improvement with antibiotic treatment was significant, as was the poor response to $100 \%$ oxygen, and recognition of this ensured that timely assistance from a tertiary centre was sought, which was ultimately life-saving.

\section{Multiple choice questions}

1. What is the most common pathogen causing early onset sepsis in preterm infants?
A. Group B Streptococcus
B. Group A Streptococcus
C. Escherichia coli
D. Stapyhlococcus aureus
E. Listeria monocytogenes

2. How many times greater are the odds of early onset sepsis if maternal vaginal culture is positive for GBS at delivery?
A. 2.4
B. 24
C. 124
D. 204
E. 402

3. In which one of the following is the mechanism of cyanosis NOT a right to left shunt?
A. Tetralogy of Fallot
B. Critical pulmonary stenosis
C. Ebstein anomaly
D. Persistent pulmonary hypertension of the newborn
E. Transposition of the great arteries

4. What is the incidence of TAPVC per 100000 live births?
A. 1.1
B. 3.1
C. 5.1
D. 7.1
E. 9.1

5. What is the most common subtype of TAPVC?
A. Supracardiac
B. Intracardiac
C. Infracardiac
D. Mixed type supracardiac and intracardiac
E. Mixed type infracardiac and intracardiac Answers to the quiz are after the references.

Contributors AJJ: significant role in drafting article, format design, critical revision, and approving final version.

Responsible for the case history and sections on pulse oximetry screening, spotting the sick neonate, and sepsis. LDS: significant role in critical revision of important content. Responsible for sections on cyanosis and TAPVC. Gave final approval. TK: conceived the original idea, and designed majority of the format. Responsible for the case history. RN: conceived the original idea. Significant role in critical revision of content. Gave final approval. ANS: significant role in critical revision of content. Gave final approval. Responsible for sections on cyanosis and TAPVC.

Competing interests None.

Patient consent Obtained.

Provenance and peer review Not commissioned; externally peer reviewed.

Open Access This is an Open Access article distributed in accordance with the Creative Commons Attribution Non Commercial (CC BY-NC 3.0) license, which permits others to distribute, remix, adapt, build upon this work noncommercially, and license their derivative works on different terms, provided the original work is properly cited and the use is non-commercial. See: http://creativecommons.org/licenses/by$\mathrm{nc} / 3.0 /$

\section{REFERENCES}

1 Newborn and Infant Physical Examination: Standards and competencies. http://nipe.screening.nhs.uk (accessed Mar 2013).

2 Knowles R, Griebsch I, Dezateux C, et al. Newborn screening for congenital heart defects: a systematic review and costeffectiveness analysis. Health Technol Assess 2005;9:1-152.

3 Hoffman JI. It is time for routine neonatal screening by pulse oximetry. Neonatology 2011;99:1-9.

4 Wren C, Reinhardt Z, Khawaja K. Twenty-year trends in diagnosis of life-threatening neonatal cardiovascular malformations. Arch Dis Child Fetal Neonatal Ed 2008;93: F33-5.

5 Bull C. Current and potential impact of fetal diagnosis on prevalence and spectrum of serious congenital heart disease at term in the UK. Lancet 1999;354:1242-7.

6 Chew C, Halliday JL, Riley MM, et al. Population-based study of antenatal detection of congenital heart disease by ultrasound examination. Ultrasound Obstet Gynecol 2007;29:619-24.

7 Hunter S, Heads A, Wyllie J, et al. Antenatal diagnosis of congenital heart disease in the northern region of England: benefits of a training programme for obstetric ultrasonographers. Heart 2000;84:294-8.

8 National Institute for Cardiovascular Outcomes Research. Antenatal Diagnosis of Congenital Heart Disease. https:// nicor4.nicor.org.uk/CHD/an_paeds.nsf/vwContent/Antenatal\% 20Diagnosis? Opendocument (accessed 19 Mar 13).

9 Hospital Episode Statistics online: Duration of stay 19752008/09. http://www.hesonline.nhs.uk/Ease/servlet/ AttachmentRetriever?site_id $=1937 \&$ file_name $=$ d: efmfiles $\backslash$ 1937\Accessing\DataTables\Maternity\Tables 11 to $20 \backslash \mathrm{Tb} 18 \mathrm{a}$ Mat_Tb18a_0809.pdf\&short_name=Mat_Tb18a_0809. pdf\&u_id=8662 (accessed 19 Feb 13).

10 Thangaratinam S, Brown K, Zamora J, et al. Pulse oximetry screening for critical congenital heart defects in asymptomatic newborn babies: a systematic review and meta-analysis. Lancet 2012;379:2459-64.

11 Ewer AK, Middleton LJ, Furmston AT, et al. Pulse oximetry screening for congenital heart defects in newborn infants (PulseOx): a test accuracy study. Lancet 2011;378:785-94. 
12 Roberts TE, Barton PM, Auguste PE, et al. Pulse oximetry as a screening test for congenital heart defects in newborn infants: a cost-effectiveness analysis. Arch Dis Child 2012;97:221-6.

13 de-Wahl Granelli A, Wennergren M, Sandberg K, et al. Impact of pulse oximetry screening on the detection of duct dependent congenital heart disease: a Swedish prospective screening study in 39,821 newborns. BMJ 2009;338:a3037.

14 American Academy of Paediatrics. Algorithm: Screening for Critical Congenital Heart Defects. http://www.cdc.gov/ncbddd/ pediatricgenetics/pulse.html (accessed 07 Mar 2014).

15 Roberton NRC. A manual of normal neonatal care. 2nd edn. London: Arnold, 1996:288.

16 Roland D. Paediatric early warning scores: Holy Grail and Achilles' heel. Arch Dis Child Educ Pract Ed 2012;97:208-15.

17 Roland D, Madar J, Connolly G. The newborn early warning (NEW) system: development of an at-risk infant intervention system. Infant 2010;6:116.

18 Polin RA The Committee on Fetus and Newborn. Management of neonates with suspected or proven early-onset bacterial sepsis. Pediatrics 2010;129:1006-15.

19 Stoll BJ, Hansen NI, Sánchez PJ, et al. Early onset neonatal sepsis: the burden of group B Streptococcal and E. coli disease continues. Pediatrics 2011;127:817-26.

20 Benitz WE, Gould JB, Druzin ML. Risk factors for early-onset group B streptococcal sepsis: estimation of odds ratios by critical literature review. Pediatrics 1999;103:e77.

21 National Institute for Health and Care Excellence. Antibiotics for early-onset neonatal infection. CG149. London: National Institute for Health and Care Excellence, 2012.
22 Yun SW. Congenital heart disease in the newborn requiring early intervention. Korean J Pediatr 2011;54:183-91.

23 Neches WH, Tatum GH, Rigby ML. Cyanosis and cyanotic spells. In: Daubeney PEF, Rigby ML, Niwa K, Gatzoulis MA, Eds. Paediatric heart disease: a practical guide. London: Wiley-Blackwell, 2012:276-9.

24 Lee JY. Clinical presentations of critical cardiac defects in the newborn: decision making and initial management. Korean J Pediatr 2010;53:669-79.

25 Kanter KR. Surgical repair of total anomalous pulmonary venous connection. Semin Thorac Cardiovasc Surg Pediatr Card Surg Annu 2006:40-4.

26 Seale AN, Uemura H, Webber SA, et al. Total anomalous pulmonary venous connection: morphology and outcome from an international population-based study. Circulation 2010;122:2718-26.

27 Seale AN, Carvalho JS, Gardiner HM, et al. Total anomalous pulmonary venous connection: impact of prenatal diagnosis. Ultrasound Obstet Gynaecol 2012;40:310-18.

28 Jones AJ, Zieba K, Starling L, et al. A clue to the diagnosis of TAPVD. BMJ Case Rep 2012;2012:pii:bcr1220115400.

\section{Answers to the multiple choice questions}

(1) C. (2) D. (3) E. (4) D. (5) A. 